\title{
O direito à saúde de pessoas trans* no Distrito Federal: entre o direito de existir e o direito à equidade
}

The right to health of transgender people in Federal District, Brazil: between the right to exist and the right to equity

El derecho a la salud de las personas trans* en Distrito Federal, Brasil: entre el derecho de existir y el derecho a la equidad

\author{
Barbara de Paula Oliveira \\ Marco Aurélio Santana da Silva² \\ Maria Socorro de Souza ${ }^{3}$
}

\begin{abstract}
Resumo
Objetivo: compreender como os movimentos sociais trans* do Distrito Federal entendem o direito à saúde. Método: tratou-se de uma pesquisa qualitativa realizada com líderes de movimentos sociais trans* do Distrito Federal em que foram realizadas entrevistas semiestruturadas e os dados foram analisados por intermédio da técnica de análise de conteúdo e agrupados em unidades temáticas. Resultado: foi possível compreender que os movimentos sociais trans* compreendem o direito à saúde como o direito de existir e o direito à equidade. Além disso, entendem também que a implementação do ambulatório trans* no Distrito Federal é uma conquista de direito à saúde. Conclusão: as pessoas trans* estão buscando serem reconhecidas como sujeitos de direito, tanto à saúde como ao direito humano mais básico, o direito de existir.
\end{abstract}

Palavras-chave: Pessoas transgênero. Minorias sexuais e de gênero. Direito à saúde. Ativismo político.

\begin{abstract}
Objective: to understand how the social movements trans* of Federal District, Brazil understand the right to health. Method: This was a qualitative research carried out with leaders of social movements trans* of Federal District, Brazil, in which semi-structured interviews were conducted and the data were analyzed through the technique of content analysis and grouped into thematic units. Results: it was possible to understand that trans* social movements include the right to health as the right to exist and the right to equity. In addition, they also understand that the implementation of the trans* ambulatory in Federal District, Brazil, is an achievement of the right to health. Conclusion: trans* people are seeking to be recognized as subjects of right, both to health and to the most basic human right, the right to exist.
\end{abstract}

Keywords: Transgender persons. Sexual and gender minorities. Right to health. Political activism.

\footnotetext{
${ }^{1}$ Mestre em Gênero e Sexualidade pelo Programa de Pós-graduação em Ciências e Tecnologias de Saúde (UnB-FCE), especialista em Saúde Coletiva pela Escola Fiocruz de Governo/Brasília. E-mail: barbara.7.oliveira@gmail.com

2 Graduado em Comunicação Social pela Faculdade Fortium, especialista em Educação em Saúde Coletiva e Atenção Básica pela UFRGS e especialista em Saúde Coletiva pela Escola de Governo da Fiocruz Brasília. E-mail: santana.marcoaurelio@gmail.com

${ }^{3}$ Escola Fiocruz de Governo - Brasília/DF. E-mail: maria.souza@fiocruz.com
} 


\section{Resumen}

Objetivo: comprender cómo los movimientos sociales del Distrito Federal, Brasil, entienden el derecho a la salud. Método: se trató de una investigación cualitativa realizada con líderes de movimientos sociales trans* del Distrito Federal, Brasil, en que se realizaron entrevistas semiestructuradas y los datos fueron analizados por intermedio de la técnica de análisis de contenido y agrupados en unidades temáticas. Resultado: fue posible comprender que los movimientos sociales trans* comprenden el derecho a la salud como el derecho de existir y el derecho a la equidad. Además, entienden también que la implementación del ambulatorio trans en Distrito Federal, Brasil, es una conquista de derecho a la salud. Conclusión: las personas trans* están buscando ser reconocidas como sujetos de derecho, tanto a la salud y al derecho humano más básico, el derecho de existir.

Palabras-clave: Personas transgénero. Minorías sexuales y de género. Derecho a la salud. Activismo político.

\section{Introdução}

Este trabalho parte do contexto atual em que a população trans ${ }^{* 4}$ entra na pauta governamental devido às lutas individuais daqueles que buscam o direito a uma identidade e dos movimentos sociais que, autorizados, tomam a representação dessas vozes e as ampliam, organizando e traduzindo os desejos da maior parte dessa comunidade. Com isso, vão construindo e mantendo espaços de diálogo com o Estado, tendo como principal objetivo a concretização das demandas dessa população.

Ao introduzir os argumentos sobre a defesa do direito humano mais básico, o direito à existência se caracteriza como a principal discussão sobre a população trans*. Como consequência do que é definido como homem/mulher normal pela sociedade, essa população se percebe, cotidianamente, em circunstâncias de preconceito, violência (física e emocional) e negligência social. A partir do conceito de cisgeneridade de Vergueiro (1), mostramos como a constituição da norma de gênero em vigor possui um papel que determina os principais sofrimentos a que são submetidas essas pessoas.

A partir da teoria do Direito achado na rua, discute-se como a defesa de direitos vem do espaço de intersecção entre todas as representações socais: a rua! O caminho para obtenção de direitos começa nas articulações entre os sujeitos, no espaço da sociedade civil (2), principalmente por considerar que o próprio direito à saúde, o Sistema Único de Saúde (SUS), se deu também por meio das lutas de movimentos sociais, como a reforma

\footnotetext{
${ }^{4} \mathrm{O}$ uso do asterisco ao referir às pessoas trans* ocorre, pois, seu uso é feito pela comunidade trans* para dizer que é um termo guarda-chuva não-binário que abrange as várias subjetividades trans* como as travestis, transgêneros, mulheres trans e homens trans.
} 
sanitária. Como apresentado por Delduque e Oliveira (3), apesar da saúde ser um direito social afirmado na Constituição Federal de 1988, ela deve ser percebida como um objeto complexo e a sua manutenção exige ações permanentes e dependentes da participação ativa de vários atores sociais além dos poderes estatais.

São muitas as pautas na saúde defendidas e exigidas pela comunidade trans*, que inclui, por exemplo, a cirurgia de transgenitalização e as terapias hormonais. Neste estudo, adentra-se no processo de implementação do principal serviço de saúde a eles destinado, os chamados ambulatórios trans*. A partir da experiência recente no Distrito Federal (DF), aproximamo-nos da história de elaboração desse projeto e, com isso, percebemos o quanto foi importante a participação dos movimentos sociais para intermediar os interesses da população trans* junto ao Governo do Distrito Federal (GDF) para a concretização da estrutura que hoje é ofertada.

Portanto, todo esse contexto é estruturado com o objetivo de compreender como os movimentos sociais trans* do DF entendem o direito à saúde.

\section{Métodos}

Trata-se de uma pesquisa qualitativa realizada com líderes de movimentos sociais trans* $^{*}$ do Distrito Federal a partir da Especialização em Saúde Coletiva da Escola Fiocruz do Governo de Brasília (DF).

A pesquisa qualitativa visa compreender os significados de ações sociais e a subjetividade dos sujeitos, considerando seu contexto social. De acordo com Minayo et al (4), o objetivo do estudo qualitativo é "compreender as relações, as visões e o julgamento dos diferentes atores sobre a intervenção na qual participam, entendendo que suas vivências e reações fazem parte da construção da intervenção e de seus resultados" ( $p$. 82). Como técnica da abordagem qualitativa foi utilizada a entrevista, pois segundo Fraser e Gondim (5), a entrevista "é uma forma de interação social que valoriza o uso da palavra, símbolo e signo privilegiados das relações humanas, por meio da qual os atores sociais constroem e procuram dar sentido à realidade que os cerca" (p. 139). A entrevista se mostra como a melhor técnica para atingir os objetivos da pesquisa, pois ela permite maior interação com os informantes-chave a fim de proporcionar a compreensão dos valores e experiências vividas pelos sujeitos em seu contexto. 
Os sujeitos de pesquisa foram informantes-chaves de lideranças de movimentos sociais no âmbito do DF que participaram, de alguma forma, na implementação do ambulatório trans*. Ao todo, foram entrevistadas duas pessoas, uma representante da União Libertária de Travestis e Mulheres Transexuais (Ultra) e um representante do Instituto Brasileiro de Transmasculinidades (Ibrat). Além desses dois movimentos, o Associação do Núcleo de Apoio e Valorização à Vida de Travestis, Transexuais e Transgêneros do Distrito Federal (Anav-Trans) também colaborou com a implementação do ambulatório, contudo, por uma questão de agenda, só foi possível entrevistar o lbrat e a Ultra, por esse motivo, neste trabalho, contamos com apenas duas de três possíveis entrevistas.

As entrevistas foram realizadas em dezembro de 2017, em local acordado com os entrevistados após contato prévio com os mesmos; foram gravadas digitalmente para otimizar a análise dos dados; e posteriormente transcritas. As perguntas foram semiestruturadas e foi utilizado um questionário com perguntas norteadoras. A pesquisa respeitou a resolução n 510/16 da Comissão Nacional de Ética em Pesquisa (Conep), do Conselho Nacional de Saúde (CNS). Portanto, só participaram da pesquisa as pessoas que assinaram o Termo de Consentimento Livre e Esclarecido (TCLE). A pesquisa foi aprovada pelo Comitê de Ética da Fiocruz sob o parecer de número 2.458.345.

Para análise dos dados, as entrevistas foram submetidas à análise de conteúdo que, de acordo com Bardin (6) consiste em analisar o que está sendo transmitido, descrevendo o conteúdo das mensagens para permitir a conclusão do entendimento dos fatores que levaram a produção e a recepção das mensagens. Uma das funções dessa técnica é a descoberta de conteúdos manifestados e implícitos, indo além das aparências do que está sendo dito. Para tanto, utiliza-se as unidades de registros (7), em que as entrevistas que passaram por esse processo, foram transcritas, identificadas em núcleos a partir do sentido extraído das falas dos entrevistados, e agrupadas de acordo com a unidade temática.

\section{Resultados e discussão}

Ao analisar as entrevistas realizadas, foi possível encontrar, como resultado da pesquisa, três unidades temáticas de sentido em relação ao entendimento que os movimentos sociais trans ${ }^{*}$ do DF têm sobre o direito à saúde. A primeira unidade entende que o direito à saúde pode ser lido como o direito de existir, que seria a busca por direitos 
humanos básicos, como ser reconhecido e respeitado em nossa sociedade. A segunda unidade mostra que o direito à saúde também pode ser lido como direito à equidade, uma vez que os equipamentos de saúde precisam se adequar às necessidades específicas da população trans*, levando assim ao exercício da equidade. Uma terceira unidade temática revela que a implementação e a participação social envolvida no ambulatório trans* do DF podem ser entendidas como uma conquista ao direito à saúde. A seguir, os resultados serão discutidos.

\section{O direito de existir}

Os movimentos sociais trans* do DF que participaram dessa pesquisa possuem como principal pauta o que Oliveira (8) chama de o direito de existir, ou seja, as pessoas trans* buscam se fazer visíveis e serem reconhecidas como sujeitos de direito dentro da sociedade cisheteronormativa. De acordo com Vergueiro (1), uma sociedade cisheteronormativa é aquela que prevê como normal a heterossexualidade e a cisgeneridade ${ }^{5}$. Todas as pessoas que vivem, em alguma medida, fora das normas binárias de gênero e sexualidade estão sujeitas a viverem à margem da sociedade e não serem reconhecidas enquanto seres humanos.

Os movimentos sociais trans* construíram suas pautas em torno da visibilidade das pessoas trans* para que pudessem ser respeitadas em suas subjetividades em relação à identidade de gênero (9). Como coloca o representante do lbrat:

A luta do movimento social trans é muito básica, por direitos básicos né, o nome social, ser respeitado. A gente tá tentando conseguir agora a carteirinha social aqui no DF, que vai ser um grande avanço porque a gente não tem nenhum documento oficial (entrevistado 1).

Por outro lado, também há, como parte do direito existir, a pauta em relação à despatologização das subjetividades trans ${ }^{*}$, como coloca a representante do Ultra:

De primeira, a nossa principal luta, o nosso principal foco é pela despatologização das identidades trans [...] Então, pensando nesse contexto internacional, a gente acredita que é melhor ficar no CID, porém, realocado numa outra categoria que não seja transtorno mental, por que aí

\footnotetext{
${ }^{5}$ Significa se identificar com o gênero que foi designado no nascimento. Ou seja, se uma pessoa nasce com vagina e é designada como sendo do gênero feminino e se identifica com ele, é considerada cisgênera. Quando não se identifica, é transgênera (1).
} 
você já é classificada como transtornada, é isso já dificulta várias questões, principalmente jurídicas e de saúde também (entrevistado 2).

O movimento pela despatologização das identidades trans* existe desde 2012. Trata-se de um movimento internacional intitulado Stop Trans Pathologization (STP), que começou no cenário espanhol e depois houve aderência de vários movimentos ao redor do mundo. Esse movimento tem como premissa a retirada da transexualidade do Manual de Diagnóstico e Estatística (em inglês, Diagnostic and Statistical Manual - DSM) e do Código Internacional de Doenças (CID), que a caracteriza como patologia psiquiátrica, bem como conferir direitos sanitários com cobertura pública de saúde e atendimentos de saúde, visando a prática da decisão informada para as pessoas trans* (10). Assim, o movimento defende que as subjetividades trans* não devem depender de diagnósticos médicos para existirem e terem direitos a saúde, pois se tratam de direitos humanos.

A questão da transexualidade ser tida como patologia, além de estigmatizar os sujeitos, é também uma barreira na mudança do nome no registro civil uma vez que é preciso um laudo psicológico e/ou psiquiátrico, alegando a transexualidade da pessoa, para que ela consiga fazer a mudança do nome. O uso do nome social e a mudança do nome no registro civil são necessidades urgentes da população trans* para que possam ter seus direitos básicos respeitados.

\section{Direito à equidade}

O conceito de equidade colocado por Barros e Sousa (11) através de pensadores desde Aristóteles a Norberto Bobbio, assevera que:

A equidade é uma adaptação da norma geral a situações específicas, pois a aplicação de uma norma genérica quando empregada literalmente, sem se levar em conta as especificidades de diferentes situações, poderia produzir injustiça (p.12).

Assim, os autores entendem que, para alcançar a cidadania plena e a justiça, a equidade seria o conceito que melhor se encaixaria para gerar situações de completo bemestar para população. No caso das pessoas trans* o direito à saúde também é visto como direito à equidade, pois, apesar de haver necessidades em saúde que são específicas dessa população, não deixa de ser também um direito humano básico. Nas falas, é 
possível enxergar que as pessoas trans* entrevistadas desejam antes de tudo ter o direito a acessar os serviços de saúde como qualquer outro cidadão que também adoece.

Eu acho que o direito a saúde é igual eu tá com uma dor de garganta e ir no hospital, tá com uma dor de coluna e ir no hospital. Mas isso é mais complicado pra gente como pessoa trans porque a gente tem que pensar se o nome social vai ser respeitado, se a gente vai pro local com o gênero certo [...] Saúde é o básico de todo mundo. A transexualidade é uma coisinha a mais. Eu tenho dor de garganta do mesmo jeito, febre do mesmo jeito... (entrevistado 1)

$\mathrm{Na}$ Constituição, consta que todo mundo tem direito à saúde, né, e etc. Nós como pessoas trans também temos direito, independentemente de ter CID ou não (entrevistado 2)

É possível compreender que o direito à saúde para as pessoas trans* é o mesmo direito que todos os brasileiros possuem com a Constituição Federal de 1988, não havendo distinção desse direito pelo fato de serem trans* ${ }^{\star}$ uma vez que também adoecem e precisam dos serviços de saúde. Entretanto, os movimentos sociais trans* também enxergam a importância da existência de serviços de saúde específicos para a população trans $^{*}$, uma vez que as necessidades de mudanças corporais pelo uso de hormônios e/ou procedimentos cirúrgicos também são relevantes no que diz respeito ao direito à saúde. Essas necessidades são parte do que colocam as pessoas trans* em situação de vulnerabilidade social e de saúde.

A questão do ambulatório trans, que é o principal equipamento de saúde que nós precisamos, no caso, de transição de gênero, né, por que outras questões de saúde, a gente pode acessar como qualquer outro cidadão, né, mas tem coisas específicas, que as pessoas trans precisam, como a transição de gênero, nenhuma outra pessoa faz transição de gênero que não seja uma pessoa trans (entrevistado 2).

Tem homens que não tem o controle da taxa assim, agora que a gente tá com o ambulatório, a gente não tinha o controle da taxa hormonal, por exemplo, aí acaba que tá há anos tomando hormônio e vai e menstrua do nada, entendeu? Sente cólica, o risco de câncer aumenta muito mais, só que muitos ainda querem ter filho (entrevistado 1)

Em uma série de artigos lançados pela revista The Lancet, em 2016, intitulado Saúde de transgêneros, foi mostrado que as pessoas trans* são mais vulneráveis à depressão, ansiedade e comportamento suicida (12). Tais vulnerabilidades poderiam ser 
melhor controladas se houvessem serviços de saúde específicos para essas pessoas, além de maior entendimento social e político das subjetividades trans* (12).

Para Sen (13), a equidade em saúde não deveria se restringir apenas na oferta do cuidado, mas levar em consideração também as discriminações que ocorrem na prestação da assistência, o que, no caso das pessoas trans*, costuma ser uma barreira de acesso aos serviços de saúde. Uma pesquisa realizada por Santos et al (14) sobre a representação social dos profissionais de saúde no Distrito Federal em relação à transexualidade mostrou que não havia representação social da transexualidade, pois os profissionais de saúde parecem não compreender completamente a transexualidade. Os profissionais a associavam à cirurgia de transgenitalização, com a ideia de que as pessoas trans* nasceram num corpo errado e por isso buscam a cirurgia para readequarem seus corpos as suas mentes e, consequentemente, há um preconceito em relação a isso, pois, para os profissionais entrevistados, as pessoas ainda teriam muita dificuldade de aceitar as diversas subjetividades. Santos et al (14) concluíram que as categorias que apareceram tinham relação com ideias de senso comum em relação à transexualidade e também com ideias que não condizem com a realidade das pessoas trans*. Portanto, não pode haver uma representação social sobre essa realidade, uma vez que, para que haja a representação social "é necessário que os atores sociais compreendam, interpretem e situem em relação à realidade apresentada" (p.4552).

Apesar da discriminação e do preconceito dificultar o acesso e a existência de serviços de qualidade para as pessoas trans*, há questões de saúde que envolvem a subjetividade trans* (8), no sentido de que nem todas as pessoas trans* desejam fazer a cirurgia de transgenitalização e necessitam de cuidados específicos, como coloca a representante da Ultra:

Mas a gente tem outras coisas, né, a gente não tem só... por exemplo, tem mulheres trans que tem pênis, então elas precisam de um urologista. Tem homens trans de vagina, entende, então eles precisam de um ginecologista. É, a maioria das mulheres trans e travestis fazem sexo anal, precisam tá indo a um proctologista, entende? Então são coisas ainda muito específicas, por mais que haja esses equipamentos, esses profissionais na área de saúde, fica complicado para uma mulher trans ter que ir num... profissional que atende homens e você ficar, né, também numa sala de espera ou estar com outros homens no ambulatório, enfim, que tenha... e o médico também te tratar todo o tempo como do gênero masculino. Então são coisas que 
A fala reforça o que asseveram Schuster et al (15) sobre especificidades de cuidados. Pessoas trans* necessitam de cuidados particulares e poderia haver um espaço próprio para o uso do nome social nos formulários médicos; sugere também que os médicos perguntem às pessoas trans* como gostariam de conduzir o exame físico e do que necessitam, assim se sentiriam mais confortáveis com os serviços de saúde. Dumaresq (16) vai além e fala sobre a desnaturalização da cisgeneridade, ao falar sobre como a escuta dos profissionais de saúde deveria considerar a cisheteronormatividade como algo anterior a sua prática. As práticas de psicologia e psiquiatria, por exemplo, são saberes que foram construídos partindo do pressuposto de que todas as pessoas são cisgênero e heterossexuais. Dumaresq (16) argumenta que uma travesti nunca chegará no consultório da mesma maneira que uma pessoa cisgênero, uma vez que a travesti carrega consigo processos de socialização estigmatizadores e, por isso, é mais facilmente julgada nos serviços de saúde e tachada com características ditas comum à sua identidade.

Dumaresq (16) fala que existe a escuta vertical e a horizontal. Na escuta vertical o profissional cisgênero está protegido pela sua normalidade, pois não foi construído sobre ele um conhecimento específico; assim há uma escuta hierarquizada em que o saber do profissional se dará de cima para baixo, não havendo argumentos possíveis das pessoas trans* $^{*}$ que atinja a realidade desse profissional para além do que foi construído sobre elas. $\mathrm{Na}$ escuta horizontal, proposta pela autora como melhor prática, há uma quebra desse saber produzido apenas sobre as pessoas trans*, aqui tanto as pessoas cisgênera como trans* são passíveis de terem verdades produzidas sobre elas, não há um contexto pressuposto de que determinadas coisas só aconteçam com as pessoas trans*.

Para que as pessoas trans* alcancem o direito à equidade, em seu amplo sentido como colocado por Sen (13), os profissionais de saúde deveriam, primeiramente, ter conhecimento sobre as subjetividades das pessoas trans* e suas necessidades de saúde para que o direito ao nome social fosse respeitado e para que os profissionais como urologista, ginecologista pudessem cuidar de pessoas trans* considerando suas dissidências de gênero. Trata-se de um grande desafio para os serviços brasileiros no sentido de que seria preciso repensar as epistemologias de gênero, pois não trata apenas 
de realização de cirurgias e uso de hormônios, os cuidados estão para além da norma binária de gênero.

\title{
Implementação do ambulatório trans* e a participação social
}

Os representantes dos movimentos sociais trans ${ }^{\star}$ compreendem o direito à saúde por meio da participação social.

\begin{abstract}
De certa forma, até um tempo atrás a gente nem tava inclusa no SUS, (...). Então, quer dizer, a gente não tava nem lá, difícil nem bom. Então, agora, pelo menos, a gente já tá num equipamento que mesmo com os problemas que ele tem, a gente tá ali. Antigamente a gente nem tava. Então (...) estamos vendo que o SUS, por mais que ele tenha essas políticas, esses princípios, ele tá conseguindo dialogar conosco e fazendo o possível para que ele possa tá abarcando essa população também. Que é o que é importante. A gente vê não só no DF, como também em outros estados do Brasil, que tem adotado o ambulatório trans, eu acho que tá sendo bem visibilizado mesmo, tá sendo uma questão onde as pessoas tão pautando muito, e tá tendo resultado. Não só em Brasília, no Distrito Federal, mas em muitos estados do Brasil, então eu acho que isso é uma vitória dos movimentos sociais, por que se não fosse o movimento social, não haveria essa visibilidade tão grande (entrevistado 2).
\end{abstract}

Podemos ver que a implementação do ambulatório trans* é um reconhecimento de inclusão dessa população no SUS. Não podemos deixar de apontar, nesse depoimento, que os movimentos sociais se percebem como atores ativos desse processo de inclusão da população trans* no SUS. Assim, é possível perceber o caminho para a construção de uma consciência que promove uma cultura de cidadania com ênfase na participação democrática. São afirmações que alimentam o conceito, transformador e libertador, do direito achado na rua. Essa expressão, criada por Roberto Lyra Filho, defende a ideia de que o direito é algo que não termina nele mesmo, é algo constante, sempre aberto a mutações, vinculado a um processo histórico, que emerge também da rua, da manifestação dos que se encontram oprimidos e excluídos da organização social vigente. O direito vai se adaptando, até se concretizar, por intermédio dos Direitos Humanos, na "enunciação dos princípios de uma legítima organização social da liberdade" (2, p 19).

Desse modo, uma vez que o contexto de construção dos serviços de saúde voltado para população trans* no DF se deu a partir dos próprios sujeitos - em uma constante negociação entre os movimentos sociais e o Estado, ou seja, um direito construído a partir da rua -, seria possível problematizar a dimensão dos movimentos sociais na 
implementação da Política Nacional de Saúde Integral da População LGBT (PNSI-LGBT) no Distrito Federal e na constituição do ambulatório trans* do DF.

Tanto a Ultra quanto o Ibrat manifestam-se em diversos espaços de discussões de políticas públicas, sempre apoiando a defesa dos interesses dessa comunidade e provocando discussões que ampliem o olhar da sociedade para a aceitação de ações que proponham caminhos mais equânimes a esse público. Conforme descrito por um dos entrevistados, o espaço onde essas lutas ocorrem:

\footnotetext{
É mais no espaço político. É muito mais no espaço político. Principalmente por estarmos em Brasília, que é uma cidade muito... que tem essa questão muito forte, né, é a capital federal, então o nosso espaço é de política mesmo, articular com, com... mesmo com um cenário às vezes não tão favorável, mas é procurar tá sempre articulando, exatamente pra que o cenário não fique ainda mais (des)favorável, então a nossa luta é ainda mais política. Também com... nessa questão de legislativa, também. Executiva, principalmente quando se trata do âmbito do DF mesmo, no caso do governador, então assim, né, esse lance do espaço de luta é mais político (entrevistado 2).
}

A implementação do ambulatório trans* concilia-se com a expectativa de uma abordagem equânime no SUS, levantando o questionamento se esse equipamento é suficiente para prestar o cuidado em saúde, identificado até o momento, como necessário ao público trans*. A PNSI-LGBT é uma normativa do Ministério da Saúde (17) que propõe reconhecer as demandas dessa população que convive com diversas situações de vulnerabilidade (18). É um documento que legitima as especificidades das pessoas trans*, amparando-se nos argumentos constitucionais sobre a equidade e, também, na Carta dos Usuários do Sistema Único de Saúde brasileiro (19). O trabalho de elaboração dessa política preocupou-se em abraçar as diretrizes governamentais expressas no Programa Brasil sem Homofobia, ação coordenada pela Secretaria de Direitos Humanos da Presidência da República (SDH/PR) (20). Desse modo, podemos defender o argumento de que, para os movimentos sociais vinculados à população trans* do DF, o ambulatório trans* conquistado recentemente amplia as possibilidades de equidade no SUS para esse segmento social.

Os movimentos sociais do DF defendem que o processo de negociação de um equipamento ou serviço direcionado a um público específico precisa contar com a participação das pessoas (ou de seus representantes) que irão usufruir determinado 
projeto. Argumentam que o ambulatório trans* inaugurado dialoga, nesse sentido, também com a PNSI-LGBT, contribuindo com a sua consolidação e implementação. Portanto, nas palavras de um dos entrevistados, esse equipamento de saúde:

Dialoga com o movimento por que nós fomos muito procuradas pra contribuir, pra que a política fosse efetiva. Pra que... simplesmente você não vai implementar um ambulatório sem escutar as pessoas que irão utiliza-lo. Então houve sim uma articulação com o movimento trans, o movimento LGBT também, como um todo, pra que pudesse melhorar, ver o que podia ser feito, foi uma coisa construída em conjunto. Foi muito legal, entendeu... E que a política de saúde foi bem efetiva com relação a isso, né! A gente sabe dos problemas que o governo, o estado, o SUS principalmente, mas pelo menos estamos inclusos nesse problema também, né! (entrevistado 2).

Contudo, há reticências sobre o projeto implementado. Nos argumentos referentes aos serviços ofertados, existe a expectativa de melhoras. Quando questionado se o ambulatório atende às necessidades da população trans ${ }^{*}$, um dos entrevistados respondeu que:

Atende basicamente. Não vou dizer que é o ambulatório que nós queríamos, mas já é um grande começo, já é uma vitória, um passo dado muito importante. Falta melhorar? Falta bastante coisa para ser melhorada. Claro que a gente... como eu disse, no âmbito do SUS a agente sabe que existe muita dificuldade, né, mas acredito que é possível ainda ter uma melhora, principalmente com o atendimento, por que ainda tá muito, é... restrito, são poucas horas de atendimento, as vezes é uma, duas pessoas por dia, entende? (...) Então depende muito de como os profissionais tão se articulando ali, naqueles horários. E mesmo por que, também, o ambulatório precisa saber quais as demandas, se vai ser efetivo o equipamento, a gente consegue compreender isso, também (entrevistado 2).

O movimento social tem a clareza de que precisa avançar, mas não deixa de pontuar sobre o momento atual, a dificuldade de colocar na agenda do GDF um tema tão provocador para uma sociedade que tem se mostrado ainda muito conservadora. Então, também por isso, celebra muito a inauguração desse equipamento de saúde.

E pro movimento, a gente tá feliz também, com certeza. Que é uma vitória, como eu disse, num cenário político conservador, e que impede que os nossos direitos avancem, é um avanço! Então é uma conquista do movimento também, por que o movimento reivindicou, o movimento teve lá brigando, o movimento teve lá pedindo. E seria ruim se não tivesse acontecido. Aconteceu, então pra nós é motivo de felicidade, é mais uma 
pauta que nós conseguimos vencer, digamos assim, mas que ela tá ali também pra ser lembrada todo o tempo, que precisa melhorar, e enfim, né, por que quando você se cala, você acha que tá tudo bem, então acaba... né, a casa fica bagunçada. Então tem sempre que tá mantendo a ordem (entrevistado 2).

Os movimentos sociais trans* compreendem ser perceptível a necessidade de melhoras nos serviços ofertados pelo ambulatório, mas o mais interessante notar é que a procura pelo equipamento foi maior que a expectativa deles.

Olha tem que melhorar bastante coisa porque é uma demanda muito grande. A gente ficou com medo de não ter muita gente. Antes da implementação do ambulatório a gente fez um levantamento pra mostrar a demanda. A gente fez um levantamento de homens trans que iam ser atendidos de primeira e eram 80. Mas aumentou muito o número de homens trans aqui no DF, já tem gente vindo aqui pro DF pra tentar a transição aqui (entrevistado 1).

Assim, para os movimentos sociais que participaram da luta para que o ambulatório trans* do DF saísse do papel, esse equipamento de saúde é motivo de muito orgulho. Para eles, há um sentimento de reconhecimento e resposta do Estado às necessidades dessas pessoas. Contudo, essas representações sociais estão cientes de que mais batalhas precisarão ser travadas. Existe ainda muito a ser feito pelo reconhecimento da identidade das pessoas trans*.

Como afirmado pela ativista Keila Simpsom, o Ministério da Saúde foi o órgão público que mais efetivou as propostas de ações para a população LGBT nos últimos anos, acolhendo as contribuições do movimento organizado, manifestadas nas conferências nacionais de políticas públicas LGBT. Ela afirma que a implementação da PNSI-LGBT, pelo debate proposto, possibilita que, cada vez mais, seja comum que essas populações possam estar presentes, sem estranhamentos, nas dependências do SUS (20). Não caberia mais discussões sobre a relevância de ter os espaços específicos na construção desse novo paradigma, agora seria fundamental continuar trabalhando para que todo 0 SUS pudesse adequar-se a esse novo fato, por meio de um processo que exija esse olhar equânime também dos profissionais que estão nos serviços para que a população trans* possa dignamente cuidar da sua saúde em locais comuns a todas as pessoas. 


\section{Considerações finais}

Muitos são os desafios para a garantia do direito à saúde de pessoas trans* no Brasil. Foi possível compreender que os movimentos sociais trans*, pelo menos no âmbito do Distrito Federal, estão preocupados com questões básicas, como o direito de existir, até as mais complexas, como o direito à equidade. Os sentidos de equidade podem avançar, ao reconhecer que pessoas com subjetividades dissidentes têm necessidades diferentes e não são menos humanas por isso.

O processo de construção de uma nova representação da identidade humana, para além da concepção homem/mulher, perpassa pela manutenção e defesa de espaços de representatividade. Como apresentado neste trabalho, um importante equipamento de saúde, específico para a população trans* foi inaugurado no Distrito Federal. É um espaço no SUS que contribui para que o tema se mantenha presente, proporcionando visibilidade.

O ambulatório trans* do DF busca replicar um modelo, que pode ser considerado inovador, existente em outros estados. Ainda em construção, o ambulatório trans* é um equipamento que ousa prestar cuidados em saúde a uma população ainda invisível para toda a sociedade e desassistida pelas políticas públicas na maior parte de suas demandas. Por isso, reconhecemos que há a necessidade de muito mais. É fundamental que haja apoio à produção de pesquisas que busquem informações sobre o perfil sociodemográfico da população trans*; que amplie os conhecimentos atuais sobre as características epidemiológicas, os seus comportamentos e práticas. Proporcionar espaços para que eles possam dialogar sobre as suas expectativas em relação à saúde será essencial para a produção de cuidados em saúde que atendam as reais necessidades dessa comunidade e contribua para a garantia do direito à saúde e à cidadania plena dessas pessoas.

Para isso, é fundamental o desenvolvimento de uma gestão participativa eficiente. Afinal, como destacado neste trabalho, os movimentos sociais foram protagonistas para que esse equipamento de saúde específico para a comunidade trans* fosse inaugurado, justamente por manter uma pressão constante junto ao GDF, por mais de um governo. Assim, o resultado deste trabalho nos destaca que o SUS não representa apenas a defesa do direito à saúde, mas principalmente um posicionamento político que preserva e valoriza um modelo de sociedade democrática, com oportunidades equânimes e mais justas. 


\section{Referências}

1. Vergueiro VS. Por inflexões decoloniais de corpos e identidades de gênero inconformes: uma análise autoetnográfica da cisgeneridade como normatividade. 2015. [Dissertação]. Salvador: Programa de Pós-Graduação em Cultura e Sociedade. Instituto de Humanidades, Artes e Ciências Professor Milton Santos. Universidade Federal da Bahia, 2015.

2. Costa AB, Sousa Junior JG. O direito achado na rua: uma ideia em movimento. In: O Direito achado na rua: Introdução crítica ao direito à saúde. Alexandre Bernardino Costa et al. (organizadores) - Brasília: CEAD/ UnB, 2009.

3. Delduque MC, Oliveira MSC. Tijolo por tijolo: a construção permanente do direito à saúde. In: O Direito achado na rua: Introdução crítica ao direito à saúde. Alexandre Bernardino Costa et al. (organizadores). Brasília: CEAD/ UnB, 2009.

4. Minayo MCS, Souza ER, Constantino P, Santos NC. Métodos, técnicas e relações em triangulação. In: Avaliação por triangulação de métodos: uma abordagem de programas sociais. Rio de Janeiro: Editora Fiocruz. 2005.

5. Fraser MTD, Gondim SMG. Da fala do outro ao texto negociado: discussões sobre a entrevista na pesquisa qualitativa. Paidéia, v.14, n.28, p.139152. 2004.

\section{Bardin L. Análise de Conteúdo. Lisboa: Edições 70, 2011.}

7. Deslandes S, Gomes R, Minayo MCS. Pesquisa social: teoria, método e criatividade. 25a ed. Rio de Janeiro: Vozes, 2007.

8. Oliveira BP. A gente não se descobre, a gente se define. As subjetividades trans* no HUB-DF. [Dissertação] Brasília: Programa de Pós-Graduação em Ciências e Tecnologias em Saúde. Faculdade de Ceilândia. Universidade de Brasília; 2017.

9. Carvalho M, Carrara S. Em direção a um futuro trans? Contribuição para a história do movimento de travestis e transexuais no Brasil. Sexualidad, Salud y Sociedad - Revista Latinoamericana, n. 14, p. 319-351, 2013. Disponível em:

http://www.scielo.br/scielo.php?script=sci_arttext\&pid=S198464872013000200015\&lng=en \&nrm=iso [Acesso em 24.fev. 2018].

10. Bento B. O que é transexualidade? $2^{\mathrm{a}}$ ed. São Paulo: Brasiliense, 2012.

11. Barros FPC, Sousa MF. Equidade: seus conceitos, significações e implicações para 0 sus. Saúde soc, São Paulo, v. 25, n. 1, p. 9-18, 2016. Disponível em: http://www.scielo.br/scielo.php?script=sci_arttext\&pid=S010412902016000100009\&lng=en \&nrm=iso [Acesso em 12.jan. 2018]. http://dx.doi.org/10.1590/S0104-12902016146195.

12. Winter S. et al. Transgender people: health at the margins of society. The Lancet. Londres, v. 388, p. 390-400, jun.2016. Disponível em: 
https://www.thelancet.com/journals/lancet/article/PIIS0140-6736(16)00683-8/fulltext [Acesso em 20.jan.2018]

13. Sen A. Por qué la equidade en salud? Revista Panamericana de Salud Publica, Washington, DC, v. 11, n. 5-6, p. 302-309, 2002.

14. Santos AB, Shimizu HE, Merchan-Hamann E. Processo de formação das representações sociais sobre transexualidade dos profissionais de saúde: possíveis caminhos para superação do preconceito. Ciência \& Saúde Coletiva, v. 19, n. 11, p. 45454554, 2014. Disponível em: http://www.scielo.br/scielo.php?script=sci_arttext\&pid=S141381232014001104545\&lng=en\&nrm=iso [Acesso em 20.jan. 2018].

15. Schuster MA, Reisner SL, Onorato SE. Beyond bathrooms - meeting the health needs for transgender people. The New England Journal of Medicine, n. 14, p. 101-103, 2016. Disponível em:

https://www.nejm.org/doi/10.1056/NEJMp1605912?url_ver=Z39.882003\&rfr_id=ori\%3Arid\% 3Acrossref.org\&rfr_dat=cr_pub\%3Dwww.ncbi.nlm.nih.gov [Acesso em 20.jan.2018]

16. Dumaresq L. Ensaio (travesti) sobre a escuta (cisgênera). Periódicus, v. 1, n. 5, p. $121-$ 131, 2016. Disponível em:

https://portalseer.ufba.br/index.php/revistaperiodicus/article/view/17180/11337 [Acesso em 10.fev.2018]

17. BRASIL. Política Nacional de Saúde Integral de Lésbicas, Gays, Bissexuais, Travestis e Transexuais. Brasília: Ministério da Saúde, 2013.

18. BRASIL. Ministério da Saúde. Carta dos direitos dos usuários da saúde. 2ª ed. Brasília: Ministério da Saúde, 2007.

19. BRASIL. Brasil Sem Homofobia: Programa de Combate à Violência e à Discriminação contra GLTB e Promoção da Cidadania Homossexual. Brasília: Ministério da Saúde, 2004.

20. BRASIL. Transexualidade e travestilidade na saúde. Brasília: Ministério da Saúde, 2015. 